\title{
The Future of ASEAN Energy Mix: A SWOT Analysis
}

\author{
Xunpeng Shi ${ }^{1}$
}

For final version, please visit Renewable \& Sustainable Energy Reviews, 53:672-680

DOI: $10.1016 /$ i.rser.2015.09.010

\begin{abstract}
This paper assesses competing outlooks for energy mix in the Association of Southeast Asian Nations (ASEAN), highlighting the paradox of its fossil fuel-dominated outlooks when contrasted with its aspirations to move toward a green energy mix, and reviews green energy strategies using the SWOT (strengths, weaknesses, opportunities, and threats) analysis method. The paper argues that despite the looming brown outlooks due to the expected surge of coal, the ASEAN region has many advantages in providing cleaner energy for its green vision. However, reduction of $\mathrm{CO} 2$ emissions has not been explicitly set in the region's policy agenda and thus green energy potential is underdeveloped. To achieve a greener energy mix, ASEAN needs to make further efforts such as cleaner use and removal of subsidies of fossil fuels, promotion of renewables and energy efficiency, regional market integration and connectivity, and execution of existing plans by nations. Ultimately, each of these strategies will require sustained leadership, political determination, and concrete actions from stakeholders, in particular, national governments across the region.
\end{abstract}

Key Words: Southeast Asia; ASEAN; Energy Mix; Energy Outlook; SWOT Analysis

\section{Introduction}

The current outlooks for the Association of Southeast Asian Nations (ASEAN) energy mix are brown: coal will have a growing share and $\mathrm{CO} 2$ emissions are expected to almost double between 2011 and 2035. With a rising population of 571 million in 2010 and economic growth resulting in an increasing share of global Gross Domestic Production (GDP), Southeast Asia is seeing rapid growth in its energy demand and is consequently shifting the center of gravity of world energy demand towards Asia, along with its neighbors China and India [1]. Such dramatic and rapid shifts create challenges in terms of providing for energy supply, energy security, and environmental management [2]. Consequently, conflicts between increasing energy use to sustain economic growth and mitigating adverse impacts on the environment-are emerging concerns in Southeast Asia that will linger on in the near future.

Paradoxically, ASEAN has stated its aspiration to be "Green". Notably, however, actions that directly reduce Greenhouse Gas (GHG) emissions have not been incorporated in the current

${ }^{1}$ Energy Studies Institute, National University of Singapore, Singapore.

Email: xunpeng.shi@gmail.com 
energy sectorial action plan. In place of direct abatement policies, ASEAN has undertaken various actions to approach a green energy mix indirectly, with some of these programs going well but require continued progress, and others insufficient to meet their stated goals.

This paper applies the "SWOT" analysis, which is popular in strategy studies, to examine the strengths, weaknesses, opportunities and threats, of the ASEAN energy sector with regards to achieving green energy in the future. To the best of the Author's knowledge, such a strategic analysis of the ASEAN energy mix in the context of de-carbonization has not been presented in the literature.

Examining the paradox and its possible solutions can help policy makers understand the current situation, the source of inconsistency in their policies, and the likely impacts of current policies. This deepened understanding could also contribute to the setting of relevant policies and action plans that can reconcile this paradox.

The paper is organized as follows. Section two outlines the paradox between the region's green ambitions and its brown outlooks. Section three presents a "SWOT" analysis of ASEAN's energy sector, highlighting strengths, weaknesses, opportunities, and threats of the future development of ASEAN's energy mix. Section four presents the results of the SWOT analysis. Section five discusses strategies that are expected to make contributions to a greener ASEAN energy mix. This paper concludes by ultimately arguing that becoming greener, while not green, is likely to be a practical goal for ASEAN's energy mix. It further notes that cleaner use and reform of subsidies of fossil fuels, promotion of renewables and energy efficiency, regional market integration and connectivity, and execution of existing plans by nations are key issues when moving towards a cleaner, more sustainable energy mix for ASEAN.

\section{The Issue: A Paradox of Brown Outlook vs. Green Vision}

ASEAN's energy consumption is expected to experience continued growth over the next two decades as a result of significant economic and population growth and a number of key factors in the energy sector, such as increasing access to electricity. According to the International Energy Agency (IEA), ASEAN's energy demand has expanded two and a half times since 1990 . With an estimated almost tripling of the regional economy and $25 \%$ growth in the region's population, ASEAN's energy demand is projected to increase by over $80 \%$ between 2011 and 2035, a rise equivalent to current demand in Japan, under the IEA's "new policies scenario" that not only incorporates all policies and measures that had been adopted as of mid-2013, but also includes other relevant commitments that have been announced [2].

Such an accelerated growth of energy demand is required, given ASEAN's low rate of access to energy, large amount of traditional biomass usage and low level of energy usage. As a developing country block, the Southeast Asian energy sector faces challenges that are typical of other developing countries. The first high profile challenge is a lack of access to electricity. As of 2012, the total number of ASEAN population without electricity is about 140 million. The population without access to electricity is mainly from in Indonesia (60 million), Myanmar (36 million), the Philippines (29 million) and Cambodia (10 million). Only four countries, that is, Brunei Darussalam, Malaysia, Singapore, and Vietnam, have electrification rates and urban electrification rates of about $100 \%$. The lack of electricity access is more prevalent in rural 
populations, as compared to urban areas. Cambodia (34\% of electrification rate) and Myanmar (32\% of electrification rate) are two countries with the lowest rural electrification ratio [3]. A lack of access to modern energy services for cooking is another high profile challenge: total regional population relying on traditional use of biomass for cooking was 280 million in 2012. In Indonesia 103 million people still rely on traditional biomass for cooking, while such figures are close to 50 million in each of the three countries: Myanmar, the Philippines and Vietnam ratio [3].

In addition to a rural electrification, increase of supply of modern energy is also a challenge. Southeast Asia's energy use per capita was just half of the global average in 2011 [2]. Energy use per capita in Brunei Darussalam and Singapore was above 7 ton of oil equivalent (toe) while Malaysia and Thailand were above 2 toe. Energy use per capita for other countries was below 1 toe [4]. The difference between the highest and the lowest are more than 78 times, which is roughly equivalent to the development gap between the richest and poorest.

In terms of electricity, Cambodia has the lowest electricity consumption per capita in ASEAN in the two studied periods (17.7 kWh in 1995 and $40.1 \mathrm{kWh}$ in 2010), while Brunei (4560.3 kWh, 1990; 8260.3 kWh, 2010) and Singapore (5151.6 kWh, 1990; 8983.0 kWh, 2010) are among the highest [4]. According to one UN report [5], which assumes the minimal need for a modern society of $2000 \mathrm{kWh}$ per capita per year, only Brunei, Malaysia, and Singapore had achieved the need for a modern society in 2010. Even Thailand, which is relatively advanced in terms of economic development, still has a gap to reach the level suggested by the UN report.

Given the lower level of access to electricity and low consumption per capita, with the much anticipated economic growth and the narrowing of development gap, energy demand in many ASEAN countries will have to dramatically grow from present levels. As demonstrated in the literature [6] and [7], there is a positive relationship between economic growth and energy demand in ASEAN.

The expected high levels of increase in energy demand will see the continued dominance of fossil fuels in the region's energy mix, even in 2035. While gas is projected to retain a $21 \%$ share in both 2011 and 2035 and oil's share will be reduced from 38\% in 2011 to $31 \%$ in 2035, coal jumps from a $16 \%$ share of the primary energy mix in 2011 to $28 \%$ in 2035 [2]. In particular, the relative abundance and cost competitiveness of coal in the region, combined with a lack of incentives for $\mathrm{CO}_{2}$ emissions reductions will boost the share of coal in the power sector, from a $33 \%$ to a $50 \%$ share in the region's generation mix between 2011 and 2035 . Thus, after having experienced double-digits annual growth rates since 1990, total demand for coal supplies in Southeast Asia is predicted to triple over the next two decades, accounting for nearly $30 \%$ of global growth [2]. Notably, this coal is also being used in situations where gas could otherwise be used.

Such an increasing use of fossil fuels, particularly coal, will lead to considerable increase in GHG emissions, assuming that today's technologies will be used. ASEAN's energy-related $\mathrm{CO}_{2}$ emissions have more than tripled since 1990 and are expected to almost triple again between 2011 and 2035. The rapid growth in primary energy supply and the dominance of fossil 
fuels will result in a corresponding 4.0\% annual growth in $\mathrm{CO}_{2}$ emissions from 1,086 million tons (Mt) in 2010 to 2,864 Mt in 2035 [2]. Compared with current estimates, the amount of expected additional $\mathrm{CO}_{2}$ emissions from ASEAN is roughly equivalent to that of the world's fourth highest emitter (Russia) and about $21.4 \%$ of emissions of the world's largest emitter (China) (in 2010 data) [8]. Such growth in regional $\mathrm{CO}_{2}$ emissions, if not offset by reductions in the rest of the world, would create longer-term threats to the region's living standards and economic vitality particularly as Southeast Asia is deemed to be very vulnerable to effects of climate change [9].

Paradoxically, in contrast to the brown energy outlook in the "ASEAN Vision 2020", the ASEAN leader envisions "a clean and green ASEAN with fully established mechanisms for sustainable development to ensure the protection of the region's environment, the sustainability of its natural resources, and the high quality of life of its people " [10]. ASEAN has embraced a green growth strategy. Since 2007, the member states of ASEAN have made a number of declarations and statements supporting climate change and ASEAN itself has been actively engaged in international negotiations on a new climate change regime [11].

Despite this emerging paradox, environmental aspect is notably absent from the existing regional energy policy agenda which is collectively documented in the ASEAN Plan of Action on Energy (APAEC) 2010-2015. As aptly argued in a seminar report by Majid [9], the consensus is that Southeast Asia ,to date, has not been up to the challenge of meeting its green ambitions. This is due to a number of factors. One reason is the enormous gulf between statements of good intentions and actions in Southeast Asia [9]. Another reason could be that climate change is not a top priority on the region's overall policy agenda because of the urgent need for further economic development and access to modern energy supplies. For ASEAN governments, improving supply of energy access is still a top priority on their energy policy agenda. Other energy issues such as cleaner use of energy and climate change may thus lack attention from the governments, particularly those having low per capita use of energy, if there are no external interventions such as international technical transfer. Moreover, the potential of renewable energies that contribute to $\mathrm{CO}_{2}$ emissions reductions without compromising energy usage has been seriously underdeveloped [12].

The absence of the environmental dimension in the regional policy agenda, combined with evidence that the regional energy mix is moving toward a more coal-dominant one indicates that $\mathrm{CO}_{2}$ emissions from the energy sector have not been appropriately checked. Thus at a regional level, the development of ASEAN's energy mix is not bounded by any reduction on $\mathrm{CO}_{2}$ emissions. Such a missing link between ASEAN vision and action plan could largely explained why such a paradox would emerge

\section{Methods}

From the above observations, ASEAN faces both advantages and disadvantages in addressing how to best strengthen the outlooks for its energy mix. Thus the sector's future trajectory is not clear. With this in mind, the study employs a SWOT analysis to highlight the potentials based on which ASEAN would be able to reconcile this paradox.

A SWOT analysis (alternatively called a SWOT matrix) is a structured planning method 
used to evaluate the strengths, weaknesses, opportunities, and threats involved in a project or in a business venture. The method was also applied to energy research including regional energy policy planning [13] and renewable energy policy review [14], which address some similar issues to the current study, but in different regional context.

The SWOT analysis examines both helpful and harmful factors that originate from both internal and external of the organization or a strategic plan. Strengths and weaknesses are internal helpful resources and hindering factors regarding the green vision respectively. Opportunities and threats are external helpful and harmful factors towards the green vision respectively (Table 1).

\section{[Insert Table 1]}

\section{Results}

We apply this analytical framework to the regional analysis to assess the ASEAN energy mix against its aspiration to be greener in the future. The results are presented in Table 1. More detailed discussion of the results are given below.

\subsection{Strengths: endowment of low carbon energy resources}

First and foremost, a core strength that ASEAN possesses as it seeks to move toward a cleaner, more sustainable energy mix is that it has vast potential for the increased use of lowcarbon primary energy sources. A recent paper [7] reports that five ASEAN countries (Indonesia, Malaysia, the Philippines, Singapore and Thailand) has an energy capacity of $234 \mathrm{GW}$ hydropower and $20 \mathrm{GW}$ geothermal. It is predicted that hydropower projects from Cambodia, Laos, and Myanmar may provide 18.9 gigawatts (GW) of power for China, $7.68 \mathrm{GW}$ for Thailand, and $5.1 \mathrm{GW}$ for Vietnam in 2025 [15]. As a reference, total electricity installed in China, Thailand, and Vietnam in 2011 was $1100.5 \mathrm{GW}, 48.5 \mathrm{GW}$, and 22.0 GW, respectively [EIA16]. As the actual share of potential hydropower resources that have been developed so far remains quite low (only 1.6\% in 2009), it could still be greatly expanded, and thus shifting the prevailing mix toward lower-carbon sources [17].

ASEAN is also rich in geothermal resource. Indonesia and the Philippines are ranked second and third in terms of installed geothermal capacity. Indonesia has the largest known geothermal resources in the world, estimated at over $27.5 \mathrm{GW}$, or about $40 \%$ of the world total. But only $5 \%$ of the potential resources has been developed, as of 2014 [18]. Given the expected increasing demand of electricity, development of ASEAN's hydropower potential could replace many planned coal fired power plants and provide greener electricity for the region without increasing generation costs. However, a recent study has found that there is no relationship between the potential of renewable energy and its generation. In some countries, the share of renewable energy in the total energy mix has declined, which implies that renewable energy was underutilized and the green policy was not properly designed [7].

Additionally, given its favorable climate, Southeast Asia as a region, is also highly suitable for solar photovoltaics (PV) and bioenergy, including in countries such as otherwise resourcepoor Singapore. Indonesia, Malaysia and Thailand are the worlds' largest producers and 
exporters of palm oil, a key source of biodiesel [19].

Yet despite this overall potential, low-carbon energy resources in ASEAN are unevenly distributed. Some countries are rich in fossil fuel resources but not in low-carbon resources; others are resource-poor overall and have limited indigenous energy potential. This further limits each individual country's choices in energy supply. This mismatch leads to a large potential for hydroelectricity in Laos, Cambodia, and possibly Myanmar that is still waiting to be tapped, even though the sustainable development of hydropower has been demonstrated by Nam Theun 2 Hydroelectric Project in Laos [20]. Such a development means that some consuming countries may need to import electricity supplies even though they can otherwise be meet by the development of domestic non-renewable power generation.

\subsection{Weaknesses: abundance of fossil fuel resources and lower willingness of}

\section{governments}

A weakness for ASEAN's energy mix is the relevant abundance of fossil fuel resources. It is estimated that the ten countries of ASEAN have 14 billion barrels of oil reserves, 286.6 trillion cubic feet of natural gas reserves, and 9,408.4 billion tons of coal reserves [2]. As of 2012, Indonesia has the biggest recoverable coal in the ASEAN region at 6,718 Mt followed by Thailand (1,505 Mt). For example, Indonesia is the world's largest exporter of thermal coal. The abundance and cost competiveness of coal motivates countries in ASEAN to use more coal rather than further develop other energy sources.

The green ASEAN vision is also undermined by a lack of progress in developing low carbon energy sources and integrating energy markets due to low willingness and limited capacity. The development of intermittent renewable energy often incurs significant challenges to the power system management and the electricity market [21, 22]. To address those challenges, they need to improve both infrastructure and management, which may discourage the developing countries to pursue intermittent but green renewable energy.

Moreover, some ASEAN governments are not willing to take actions on cleaner energy, which can be demonstrated by two factors. First, many member countries, such as Indonesia, have state-owned utility companies, and thus have the channel to adopt higher efficiency coal fired power plants and pursue cleaner use of coal if the government wishes to. But the fact that this is not happening indicates that government may not be willing to do so. Energy efficiency is another example. Even though it is almost unanimously agreed that increased energy efficiency is beneficial and feasible, it has not been implemented in many countries. In addition, some members may not want to be integrated with others. One reason is that the government may be too weak to move the integration forward. For example, Cambodia may feel vulnerable given its early stage of state building and an integration could undermine the nation building efforts. Other less developed countries, or countries with different regimes, such as Myanmar and Vietnam, may be not willing to be assimilated by an ASEAN identity. Empirically, it has been shown that the biofuel development of ASEAN countries is motivated by several factors, mainly their concerns for energy security and socio-economic development, while not climate change mitigation [23] 


\subsection{Opportunities: growing new demand, looming supply-demand gap and ASEAN}

\section{Economic Community (AEC) building}

The region's projected rapid demand growth means that many new energy projects will be constructed. Those new projects are often free from vested interests and sunk costs and thus are more likely to be designed as green than retrofitting of existing projects.

ASEAN's looming energy supply-demand gap, while raising some stakeholder concerns about supply security, will create greater incentives for the development and use of new, energy efficiency technologies and renewable technologies such as solar, and wind power, among other greener supplies. The supply-demand gap will keep increasing over an outlook horizon of 20 years, leading to growing import dependence, particularly for oil and natural gas supplies [2]. It is estimated that ASEAN's net imports will rise from 1.9 million barrels per day $(\mathrm{mb} / \mathrm{d})$ to just over $5 \mathrm{mb} / \mathrm{d}$. Thus oil import dependency will increase from $44 \%$ in 2011 to $75 \%$ in 2035 . ASEAN will become the world's fourth-largest oil importer, behind China, India, and the European Union [2]. Greater pursuit of these strategies could provide opportunities for meeting ASEAN's green growth aspirations.

Another key opportunity for ASEAN to achieve its green growth goals lies in pursuing the achievement of the ASEAN Economic Community (AEC) by 2015. The AEC provides an institutional framework for the integration of energy markets in ASEAN and should facilitate integration and cooperation in the region's energy sector. The AEC Blueprint consists of four pillars that are interlinked with each other, namely fostering (1) a single market and production base, (2) a competitive economic region, (3) equitable economic development, and (4) integration into the global economy. A single market and production base is a key aspect of an integrated energy market and will allow low carbon resources such as hydro, biofuels and geothermal to be exported to other countries [24].

The AEC Blueprint also envision two major infrastructure projects, namely the ASEAN Power Grid (APG) and the Trans-ASEAN Gas Pipeline (TAGP, the realization of which will make regional trade of electricity and natural gas possible [24]. The APG, which was first proposed in the 1990s, aspires to form a regional wide power grid that would make it possible to trade electricity across the region so that electricity may be generated from more efficient and environment-friendly sources. The TAGP has also been prosed along with the APG to encourage the use of natural gas as well as to ensure the reliability of gas supply for ASEAN member states. However, the current action plan on energy cooperation, APAEC 2010-2015 [25], does not mention the introduction of a regional unified energy market.

\subsection{Threats: fragmented energy markets and networks, nationally focused energy} security paradigm and prevailing fossil fuel subsidies

Currently, there is no unified ASEAN regional energy market and no single regional network of electricity. Power grids are largely confined by national boundaries. For the future, all the 16 trans-boundary power grid connections under APG plan are bilateral and the existing five cross-border energy exchanges are limited to zero exchange or pre-established purchase agreements (bilateral) [24]. By 2020, there are likely to be only a few interconnected national power grids in ASEAN and these will offer bilateral exchanges of electricity and emergency 
backups. Even if all sixteen interconnection systems are completed, a regional power grid is still far away, as those systems are largely bilateral connections. The Heads of ASEAN Power Utilities/Authorities (HAPUA) has yet to come out the vision about the integrated ASEAN Power Grid [26]. There is also no clear vision about whether the APG should be an integrated and harmonized single grid, or a few heterogeneous national grids that are linked by an ASEAN-wide backbone power grid [24]. Such a lack of energy connectivity makes it impossible to trade electricity across the region and also impossible to utilize the low carbon resources given the geological mismatch of resource sites and demand centers.

Even though the natural gas has an on-shore regional wide network, there is no regional wide natural gas trade. Although only 3,300 km of TAGP pipeline connections will be in operation by 2015 , it is already possible to transmit gas from Myanmar to Vietnam or even to Indonesia. It is also possible for Singapore to export gas from its liquefied natural gas (LNG) imports to Thailand through the existing pipeline connection [26]. However, there is a likely case in which no indigenous gas may be transported by TAGP in the future. The East Natuna gas field, which is expected to be the main supply source for the TAGP, does not appear to be attractive on a purely commercial basis [26]. Additionally, even with the development of the Natuna gas field, ASEAN is still facing widening gaps between supply and demand from 2017 onward [27].

The region's current energy security paradigm is a factor behind the fragmentation of the energy markets. Rather than thinking of energy security as a regional challenge, many countries are focused on securing their own national energy security, thus limiting the potential regional cooperation. Such a mindset is one of the main drivers in the current development of power exchanges and project interconnections, and has resulted in a number of structural limitations. An example of such a fear coming into play is the case of the Sabah-Brunei line, which was planned to deliver hydropower to Brunei. Given the price advantage of hydropower over gasfired electricity, this line would have reduced generation costs and $\mathrm{CO}_{2}$ emissions in Brunei. Yet it was dropped from the current APG plan due to concerns about security of supply in Brunei. Consequentially, it can be observed that a prioritization of national energy security over regional energy security can become a barrier to future energy cooperation and thus limit the success of achieving a greener energy mix. Such a limitation to trade in energy will prevent the optimal use of energy resources in the region, which can gain from a more open market (Chang and $\mathrm{Li}, 2012$ ).

Another threat is the prevailing subsidy to fossil fuels, which limits ASEAN's ability to develop greener energy sources. The degree of energy subsidies in many ASEAN countries are above the global average level. The IEA estimated that in 2011, the total cost of fossil fuel subsidies among the countries of ASEAN amounted to \$51 billion [2]. In 2011, the after-tax energy subsidies on petroleum products, electricity, natural gas, and coal amounted to a share of GDP that was roughly $8.41 \%$ in Brunei, $5.36 \%$ in Indonesia, $7.21 \%$ in Malaysia, and $4.72 \%$ in Thailand, compared with a world average of only $2.72 \% .^{2}$ In terms of the ratio of energy

2 According to the International Monetary Fund, consumer subsidies include two components: a pre-tax subsidy (the difference between the price paid by consumers and supply and distribution costs) and a tax subsidy (when taxes are below their efficient level). 
subsidies to overall government budgets, the government of Malaysia had the highest ratio at about $32.94 \%$, followed by $30.07 \%$ and $20.85 \%$ in Indonesia and Thailand, respectively. Of this set, Brunei has the lowest ratio, coming in at $13.51 \%$. However, compared with a world average of $8.13 \%$, financial energy subsidies still account for too high of a share of government spending in ASEAN [28]. The low oil price at the end of 2014 made it possible for Indonesia [29] and Malaysia [30] to overhaul or remove fossil fuel subsidies. However, if the oil prices increase again, the subsidies may come back as the fundamental of subsidies policy has not been changed in ASEAN [29].

Subsidies will not only discourage investment in clean energy, fossil fuel exploration, and infrastructure, but also prevent greater integration of regional energy markets and thus making it impossible to optimize the trade of low-carbon resources at a regional level [31]. With the presence of heterogeneous subsides in neighboring countries, a country with higher subsidies may decide to "strengthen the fence" along its boundary to prevent a leak of its subsidies to others. For example, in order to prevent cars from Singapore benefitting from subsidized fuels in Malaysia, the Malaysian government banned the sale of fuel to foreign cars in the areas bordering Singapore and Thailand. As a response, the Singaporean government set the requirement that anyone leaving Singapore in a Singapore-registered motor vehicle must have more than three-quarters of a tank full of motor fuel [31]. Such a "border closure" policy works against fulfilling the need for energy market integration, and the implementation of such closedborder policies is costly. Ultimately, such a fragmented energy market will limit ASEAN's utilization of low-carbon energy resources by continuing the mismatch between available resource endowments and regional access to supplies to meet energy demand.

\section{Discussion: ASEAN strategies for a greener and cleaner energy}

\section{mix}

The SWOT analysis shows that although ASEAN has vast potential for greater use of lowcarbon emission energy resources, it is unlikely to shift away from fossil fuels, and thus a complete green vision is not attainable. However, with an appropriate action plan, ASEAN's energy mix can still be greener and cleaner. Based on the SWOT analysis and the SWOT framework, we propose the following strategies: in the strengths-opportunities case, ASEAN needs to promote renewable energy and energy connectivity; in the strengths-threats case, ASEAN needs to shift its security paradigm, build political trust and seek deliverables from nations; in the weaknesses-opportunities case, ASEAN can promote energy efficiency to reduce overall energy demand and cleaner use of fossil fuels. In the weakness-threat case, fossil fuel subsidy reform facilitated by national government willingness and capacity will be necessary (Table 2).

Table 2 Proposed strategies for a greener ASEAN energy mix 


\subsection{Cleaner use of fossil fuels and phasing out of subsidies}

Given the outlook that about $50 \%$ of the region's electricity will be generated from coal fired power plants [2], the cleaner use of coal will be a crucial issue for ASEAN and coal should be key issue of policy debates. Ignoring the presence of fossil fuels in national mixes in policy debates will worsen the environmental performance of these countries, as realistically coal is the only indigenous energy source that can meet growing demand for energy to sustain economic growth in the near future [32].

The development and application of clean coal technologies (CCTs) are key to reconciling the tensions between coal use and the environment. The adoption of CCTs, however, does not automatically come from cost minimization of users. Regulatory coercion and economic incentives are necessary to force coal users - particularly the large-scale users such as steel makers and power generators - to use CCTs. However, progress on adoption of and cooperation on coal \& CCT areas in ASEAN is only at the early stages. Adoption of highefficiency coal-fired power plants in member countries is constrained by cost concerns, since affordability is a big issue in the developing countries of ASEAN [24]. Even more unfortunately, coal-fired power plants with little application of CCTs are even relocated to less developed countries. For example, the Electricity Generating Authority of Thailand built coal-fired power plants in its neighboring countries after facing internal public resistance to coal-fired power plants. Such relocations usually worsen the emissions performance of these plants: if the power plants were built in Thailand, the stricter Thai policy and regulatory regime would have led to the installation of better and more CCTs. This example highlights the need to address fossil fuel issues and formulate consistent regional policy. Additionally, many ASEAN developing countries need financial aid, technical transfers and cooperation mechanisms to invest in CCTs and low carbon technologies[25].

The cleaner use of fossil fuels must be supported by removing the fossil fuel subsidies. Although ASEAN has declared an intention to remove or reduce fossil fuel subsidies, movement on the issue is proceeding slowly. Plans or actions for liberalizing energy prices and removing subsidies for fossil energy have been implemented in many countries, such as Indonesia, Malaysia, and Vietnam, and the list of countries making commitments to reform energy pricing has been growing [2]. Brunei replaced a regressive electricity tariff with a progressive electricity tariff from January 1, 2013 [33]. Indonesia increased prices for gasoline by $44 \%$ and diesel by $22 \%$ in June 2013 [2]. On September 3, 2013, the Malaysian government decided to cut fuel subsides for the first time since 2011, which will raise the price of certain gasoline and diesel fuels by $10.5 \%-11.1 \%$. In Vietnam, a roadmap for energy price increases has been formulated, but so far implementation has lagged behind [34]. The International Monetary Fund indicated that the Indonesian fuel subsidy reform conducted in 2008 was partially successful, while fuel and electricity reform in Philippines was successful [28].

Reforming fossil fuel pricing mechanism is the major challenge that ASEAN governments have to overcome. Phasing out of fossil fuel subsidies is politically sensitive and need careful planning and actions. If the public is not convinced of the merits of removal, a subsidy removal could induce unrest and possibly even riots; fuel subsidy removal is also often used as a weapon in domestic politics [31]. Given the political sensitivity to and scale of energy subsidies in 
ASEAN, efforts addressing the removal of energy subsidies will need to be well planned, agreed upon by major stakeholders, and carefully implemented after conducting the necessary campaigns and educational outreach to the public [31]. All of these preparations will take time, but the first steps toward them should begin as soon as possible. Philippines has successfully removed energy subsides although it is still a developing country. However, such policy has profound economic consequences. According to one source, the Philippines' electricity prices (averaged at 24 US cents per $\mathrm{kWh}$ ) was the fifth highest in the world in 2013 and have crowded out industry [35]. However, many ASEAN governments either lack willingness, or capacity to address this challenge.

\subsection{Promotion of energy efficiency and renewable resources}

Increasing energy efficiency is a key strategy that could contribute to reconciling increasing demand for energy access with emission reductions. Currently, ASEAN has a regional target to reduce its energy intensity by at least $8 \%$ by 2015, based on 2005 levels [25]. ASEAN is also assessing a new target for beyond 2015, which was agreed on by APEC (AsiaPacific Economic Cooperation) leaders, that would propose reducing energy intensity by a further $45 \%$ by 2035 , compared with that of 2005 [34]. To date, all of the countries within ASEAN have hit their energy saving targets, and many have adopted various policy measures to promote energy efficiency. More than half of ASEAN has minimum energy efficiency standards and a majority of ASEAN has energy labeling programs [2].

Although much progress has been achieved over the last decade, ASEAN's achievements on energy efficiency are still quite conservative when compared with those in the rest of the world. Between 1980 and 2011, energy intensity in ASEAN improved by only 12\% overall, compared with an improvement of $26 \%$ worldwide- $38 \%$ in member countries of the Organization for Economic Co-operation and Development (OECD), 74\% in China, and 44\% in India [34]. Currently, ASEAN's energy intensity is still more than twice that of the OECD average. According to the IEA's estimations, even assuming that all current energy efficiency plans are implemented and achieved, ASEAN's estimated intensity reductions will only account for one-quarter of the economically viable reductions that could be potentially undertaken. Greater progress is limited for reasons such as not implementing building energy efficiency regulations, having a lack of mandatory standards for appliances, requiring lower fuel-economy standards, and having a lack of market-based energy prices [2]. Furthermore, the level of implementation of energy efficiency policies is quite different across countries. Singapore, Thailand and Malaysia have adopted most policy instruments while Cambodia, Laos, and Myanmar have barely made any concrete actions [34].

Energy efficiency, although important, alone cannot guarantee a green ASEAN. Even assuming the adoption of economically and commercially viable energy efficiency technologies and practices, the total energy demand is likely to be reduced by $13 \%$ (equivalent to Thailand energy demand in 2011) while $\mathrm{CO}_{2}$ emission reduction is slightly higher at $19 \%$. However, coal's share in the energy mix will still be increased from $16 \%$ in 2011 to $24 \%$ in 2035 [2]. Technical breakthroughs in energy efficiency, promotion of renewable energy, policy changes and regional cooperation and all measures are required to be used.

ASEAN renewable energy has the potential to change future outlooks. But ASEAN 
renewable energy programs still face challenges, and limits on available financial resources from the governments who have restrained development. ASEAN has set a collective target of $15 \%$ of installed power generation capacity for regional deployment that has already been achieved by 2013 [24]. Brunei has announced that it will have a 10\% share of renewable energy in its power generation mix, but the specific policies for achieving this have yet to be revealed [36]. Malaysia, the Philippines, and Thailand have implemented a feed-in tariff (FIT) program for resident renewable power generation. For example, Thailand's FIT for solar was suspended due to lower rate of realizing FIT applications. The development of renewable energy and energy efficiency in ASEAN countries, however, may have to overcome some common ASEAN barriers such as lack of funding, lack of experience and knowledge and limited policy frameworks as well as some country specific barriers [12].

\subsection{Regional energy markets integration and connectivity enhancement}

In order to optimize resources across ASEAN and achieve a green energy mix, an integrated energy market is needed. An integrated electricity market will allow surplus hydropower resources to be developed, replacing the use of coal in power generation. Due to the cost competiveness of hydroelectricity, such a substitution can be acceptable even in developing countries. Energy market integration can also increase access to electricity through stimulation of investment and utilization of neighboring grids. The pooling of resources from national grids offers additional security of supply for each country. In an integrated market, countries with more limited options for engaging renewable energy domestically, such as Singapore, will provide additional market demand for renewables from resource rich countries without necessarily requiring investment in additional capacity. An integrated regional power market can also reduce vulnerability to variability of renewables, since in a large geological area, peak demand and production of various renewable sources may have different cycles, and thus these resources can complement one another. Higher potential market penetration by renewable energy such as hydro, wind, and solar power under an integrated energy market scenario can make for a green overall mix, and can thus reconcile addressing energy demand growth and mitigating $\mathrm{CO}_{2}$ emissions.

Current working plans for energy connectivity should be enhanced to enable regional-wide energy trade that would occur under integration of energy markets. The APG plan needs to be updated to incorporate a vision for a region wide power grid that allows for the free flow of electricity with practical action plan to construct physical networks and set institutional arrangements. The emerging approach to fill the widening gaps in gas demand and indigenous supply is to bring the construction of LNG regasification terminals into the TAGP master plan. The LNG terminals provide additional flexibility to the ASEAN gas market, provided that interconnections between LNG terminals can be achieved through altering the destinations of LNG tanks. The current TAGP master plan can also be revised so that existing pipelines may be used to transport gas from some shared LNG regasification terminals and LNG can be utilized where it will be most cost effective.

Developing institutional infrastructure (also known as soft infrastructure) should be considered as important as developing the physical infrastructure for energy trade, and its development should match the sector's overall connectivity. For regional energy markets to 
function properly, both physical and institutional infrastructure need to be in place. To make the physical infrastructure workable, institutional components such as a regulatory framework, the harmonization of technical standard codes and guidelines, and legal and regulatory frameworks should be in place. However, all of these necessary pieces of soft infrastructure are still under development in ASEAN [24]. One main reason for the slow progress of the soft infrastructure could be that they are subjected to behind-the-border barriers.

The behind-the-border institutional changes within AMSs should be placed at the top of the agenda in order to move towards the AEC, with the ultimate aim of an open, competitive, and transparent energy market. The improved institutional framework across countries would provide strong legal protection, reduce transaction costs to businesses, enhance investor confidence, and enable the free flow of goods, services and capital. Therefore, political commitment that will remove major barriers towards a regional energy security will be critical and urgently needed. This political commitment can be encouraged by the progress in a broad regional integration, such as the ASEAN Economic Community that due to be realized in 2015.

Countries should jointly pursue collective energy security. A paradigm shift in ASEAN, from looking at national and fragmented energy security to regional and integrated energy security, is necessary to secure regional cooperation. A regional energy security strategy can generate better security for each country as it will open up ASEAN to foreign investment and energy supply, providing a chance for optimizing the use of energy resources [31]. To that end, ongoing efforts toward implementing the AEC can provide a legal framework where all members can cooperate on energy to optimize the use of low-carbon resources in the region to meet the rapidly growing demand. The development of GMS demonstrates that dialogues facilitated by independent organizations, such as the $\mathrm{ADB}$, can facilitate cooperation and overcome the barriers from distrust.

The change of perception of energy security mush be supported by political trust among ASEAN member countries. This lack of political trust is the key reason behind the nationfocused energy security paradigm. Once a physical network is established and supply is set relying on the cross-border trade, importers could be hurt by a supply interruption; such interruptions could be caused by political disputes as well as economic and technical reasons. One example of such a disruption due to political reasons is Russia's suspension of gas supply to the European Union in 2009 [37]. To overcome such fears and transit from national energy security paradigms to regional ones will require efforts to facilitate strong trust in ASEAN.

\subsection{Activating National government}

The willingness, capacity and actions of national governments shall always be highlighted and behind-the-border institutional changes should be put at the top of the agenda. Member countries are the key players for change in the energy outlooks as they are the ones who make changes in things and work on the ground. Regional plans and agreements should be reflected in the domestic policies and planning of individual ASEAN member states. The end goal is to enhance individual national energy policies and planning activities and to integrate them into a cohesive and effective regional energy policy with analysis and planning towards sustainable development.

Enforceable ASEAN collective vision and strategies will help national governments move 
ahead. ASEAN needs to formulate its plan of action on climate change, which shall mandate green growth as a member's national policy priority. Although ASEAN has recognized the importance of sustainable development and declared an intention to build a green ASEAN, it has yet to explicitly incorporate the environmental dimension (climate change and sustainability) into the action plan (APAEC 2010-2015). ASEAN collectively does not have a binding target, although some member countries have made some efforts toward setting national $\mathrm{CO}_{2}$ emission reduction targets [38]. A 'green ASEAN', which takes into account the impacts of climate change and sustainability, should be incorporated into the future AEC Blueprint and its action plans. This will make the green vision consistent with action plans and thus make it a deliverable plan. The regional visions and agreements should be implemented through either binding agreements or peer reviews.

Regular monitoring and assessment should be conducted to inform policy makers on the progress and create peer pressure for national governments to execute their actions plans according to their commitments. Currently, all efforts at the national level within the member states of ASEAN have been undertaken voluntarily, which is consistent with ASEAN's principle of making decisions by consensus. However, this approach suffers the drawback of leading to unnecessarily slow development. Without changing the political principle of consensus, some peer review mechanisms, such as the APEC Peer Review on Energy Efficiency, could be introduced to help members achieve their regional commitments [33].

To make things happen at the national level, some ASEAN members' capacity for formulating and executing national policy agenda has to be enhanced. ASEAN should enhance its cooperation with dialogue partners, such as the World Bank, USA, Japan and EU, who can provide the technical and financial resources and help build capacity in energy policy and planning.

\subsection{Contribution of the strategies to a greener ASEAN}

Among those proposed strategies, promotion of energy efficiency and renewable energy and cleaner use of coal are direct and technical strategies; fossil fuel subsidy reform and energy market integration are direct and institutional strategies; while national government capacity and willingness building, energy security paradigm shift, and political trust building are indirect strategies that can provide support to the other direct strategies. For those direct strategies, it is possible to measure their impact. While such a measurement is out of the scope of the current paper, some attempts in the literature could offer useful references.

The contribution of energy efficiency and renewable energy to the green vision is more straightforward. According to IEA's [2], in the case of the "Efficient ASEAN" scenario, in which all known energy efficiency measures and practices that are economically viable will be realized, in 2035 and compared with the "New Policies Scenario", the ASEAN region can reduce total energy demand from 1,004 Mt to $870 \mathrm{Mt}$ (13\%) and reduce total CO2 emissions from 2,284 Mt to 1,860 Mt (19\%). Further advancement of coal fired power plants and increase in their thermal efficiency could also reduce $\mathrm{CO} 2$ emissions. For example, ultra-supercritical steam cycles, which is not listed in the IEA Efficiency Policy Scenario, can further help reduce $10 \%$ emissions if they are operating at $48 \%$ efficiency level [39].

Replacing coal with gas in the short term and renewables in the long term could further 
reduce the emissions from increased power generation. In the case of power generation, the emissions of natural gas is about $40-50 \%$ of that of a coal-fired plant [39]. In the case of renewable energy, if the share of renewables is increased from $10 \%$ to $15 \%$ in 2035 in the Efficient ASEAN Scenario [2] to replace coal fired power generation, about $12 \%$, or $80 \mathrm{Mt}$ of coal consumption and $162 \mathrm{Mt}$ of $\mathrm{CO} 2$ emissions would be saved.

The impact of more sophisticated strategies on the green vision can be drawn from the literature. In the case of subsidies, by using a multi-regional CGE approach, Kojima and Bhattacharya [40] found that even a partial removal of energy subsidies results in benefits of market efficiency improvement. It is estimated that a per annum subsidy reduction of approximately US\$ 500 million in the EAS region could improve the regional economic condition in terms of real GDP by around $0.05 \%$ while reducing emissions by about $0.5 \%$ compared with the baseline with no such subsidy reduction.

In the case of energy market integration, Chang and $\mathrm{Li}$ [41] demonstrated that a more open power trade regime in ASEAN would encourage the development of renewable sources of power generation and thus reduce $\mathrm{CO} 2$ emissions. Opening power trade within the ASEAN region will encourage countries to draw cheaper hydropower from the countries in the Greater Mekong Sub region such as Lao PDR and Cambodia. Specifically, the new hydropower capacity in ASEAN will increase from $37 \mathrm{GW}$ in the no trade of electricity scenario to $58 \mathrm{GW}$ when countries allow up to $20 \%$ of their electricity to be imported.

\section{Conclusion and policy implications}

With the anticipated continued economic and population growth in Southeast Asia, alongside increasing urbanization and overall regional development, ASEAN's energy demand will dramatically increase over the next two decades. Such energy outlooks are unfortunately shadowed by increasing share of coal. Such brown energy outlooks are in stark contrast with the regional block's declared vision of green development.

The SWOT analysis demonstrates that ASEAN will have both numerous opportunities and various challenges to pursue a cleaner, more sustainable energy mix. The development of abundant but unevenly distributed low-carbon resources requires regional interconnection and energy market integration, which is undermined by the national security paradigm and heavy presence of fossil fuel subsidies. The abundance of fossil fuel resources is also a weakness for achieving the region's green vision. Yet efforts at achieving ASEAN's green vision are boosted by growing new demand, a looming supply-demand gap in non-renewable resources and by efforts at building an ASEAN Economic Community. Still, the pursuit of individual national energy security strategies, due partly to a lack of political trust, limits the scope for optimizing energy resources and minimizing generation costs at a regional level. Also a lack of actions due to low willingness and capacity limit of some national governments will further limit the execution of plans.

With proposed strategies and associated actions, ASEAN can achieve a greener energy mix. ASEAN could facilitate the achievement of a greener and more sustainable future energy mix by promoting cleaner use of fossil fuels, gradually phasing out fossil fuels subsidies, adopting renewable energy and energy efficiency programs, fostering greater regional 
integration and energy connectivity, shifting current energy paradigms to more regionally minded views of energy security, and enhancing execution of in-place action plans in member countries. Ultimately, each of these strategies will require sustained leadership, political trust and concrete actions from stakeholders, in particular, national governments across the region. The quantified impact of some of those strategies support that argument that ASEAN can be greener.

Acknowledgements:

This paper was developed from a 2014 Pacific Energy Summit Working Paper that was commissioned by the National Bureau of Asian Research (NBR). The author is grateful for the valuable comments from Philip Andrews-speed, Clara Gillispie, Noelan Arbis, and the NBR team and for the editorial comments from Hari M P and Jacqueline Tao Yujia. The views in this paper are those of the author and not necessary reflect those of any organizations.

\section{References}

[1] IEEJ. The Asia/World Energy Outlook 2012. Tokyo: Institute of Energy Economics, Japan; 2013.

[2] IEA. Southeast Asia Energy Outlook. Paris: International Energy Agency; 2013.

[3] IEA. World Energy Outlook (WEO) 2014 Energy Access. http://www.worldenergyoutlook.org/resources/energydevelopment/\#d.en.8630 [Accessed on 9 March 2015].

[4] Kimura S. Analysis on Energy Saving Potential in East Asia. ERIA Research Project Reports. Jakarta: Economic Research Institute for ASEAN and East Asia; 2013.

[5] AGECC. Energy for Sustainable Future. New York: United Nations Secretary-General's Advisiory Group on Energy and Climate Change; 2010.

[6] Yoo SH. The causal relationship between electricity consumption and economic growth in the ASEAN countries. Energy Policy. 2006;34:3573-82.

[7] Bakhtyar B, Sopian K, Sulaiman MY, Ahmad SA. Renewable energy in five South East Asian countries: Review on electricity consumption and economic growth. Renewable and Sustainable Energy Reviews. 2013;26:506-14.

[8] World Bank. World Development Indicators 2014. Washingtong, D.C.: The World Bank; 2014.

[9] Majid M. Climate Change: Is Southeast Asia up to the challenge? Climate Change:Is Southeast Asia Up to the Challenge. London: LSE IDEAS; 2010.

[10] ASEAN website. ASEAN Vision 2020. http://www.asean.org/news/item/aseanvision-2020 [Accessed on 18 Oct 2013].

[11] Letchumanan R. Is there an ASEAN policy on Climate Change? Climate Change:Is Southeast Asia Up to the Challenge. London: LSE IDEAS; 2010.

[12] Lidula NWA, Mithulananthan N, Ongsakul W, Widjaya C, Henson R. ASEAN towards clean and sustainable energy: Potentials, utilization and barriers. Renewable Energy. 2007;32:1441-52.

[13] Terrados J, Almonacid G, Hontoria L. Regional energy planning through SWOT analysis and strategic planning tools.: Impact on renewables development. Renewable and Sustainable Energy Reviews. 2007;11:1275-87. 
[14] Chen W-M, Kim H, Yamaguchi H. Renewable energy in eastern Asia: Renewable energy policy review and comparative SWOT analysis for promoting renewable energy in Japan, South Korea, and Taiwan. Energy Policy. 2014;74:319-29.

[15] Piseth C. Case studies of the Greater Mekong Sub-region: a pioneer of regional integration in power trade and hydropower development. 2nd Meeting of ERIA's Working Group on Energy Market Integration in East Asia (FY2013-2014) Jakarta2014.

[16] EIA (Energy Information Agency). International Energy Statistics -Total Electricity Installed Capacity. http://www.eia.gov/cfapps/ipdbproject/IEDIndex3.cfm?tid=2\&pid=2\&aid=7 [Accessed on 12 June 2014].

[17] Kimura S. Analysis on Energy Saving Potential in East Asia. ERIA Research Project Reports. Jakarta: Economic Research Institute for ASEAN and East Asia; 2011.

[18] Geothermal Energy Association. Geothermal 101-Basics of Geothermal Energy. Geothermal Energy Association,; 2014.

[19] Obidzinski K, Andriani R, Komarudin H, Andrianto A. Environmental and social impacts of oil palm plantations and their implications for biofuel production in Indonesia. Ecology and Society. 2012;17:25.

[20] Porter IC. Sustainable Hydropower Can Benefit Us All. http://web.worldbank.org/WBSITE/EXTERNAL/NEWS/0, contentMDK:21465445 me nuPK:51340358 pagePK:64257043 piPK:437376 theSitePK:4607,00.html [Accessed on 13 June 2014].

[21] Moghimi Ghadikolaei H, Ahmadi A, Aghaei J, Najafi M. Risk constrained self-scheduling of hydro/wind units for short term electricity markets considering intermittency and uncertainty. Renewable and Sustainable Energy Reviews. 2012;16:4734-43.

[22] Moghimi H, Ahmadi A, Aghaei J, Rabiee A. Stochastic techno-economic operation of power systems in the presence of distributed energy resources. International Journal of Electrical Power \& Energy Systems. 2013;45:477-88.

[23] Kumar S, Shrestha P, Abdul Salam P. A review of biofuel policies in the major biofuel producing countries of ASEAN: Production, targets, policy drivers and impacts. Renewable and Sustainable Energy Reviews. 2013;26:822-36.

[24] Shi X, Malik C. Assessment of ASEAN Energy Cooperation within the ASEAN Economic Community. Jakarta: Economic Research Institute for ASEAN and East Asia; 2013.

[25] APAEC. ASEAN Plan of Actions for Energy Cooperation 2010-2015. http://aseanenergy.org/index.php/about/apaec [Accessed on 15 April 2010].

[26] ACE, KEEI. Development of ASEAN Energy Sector. Jakarta: ASEAN Centre for Energy; 2013.

[27] ASCOPE. Trans-ASEAN Gas Pipeline (TAGP) Updaed Masterplan 2008. Jakarta: ASEAN Council for Petroleum (ASCOP); 2008.

[28] IMF. Energy Subsidy Reform: Lessons and Implications. Washington, D.C: International Monetary Fund (IMF); 2013.

[29] The Jakarta Post. Fuel subsidies completely overhauled. http://www.thejakartapost.com/news/2015/01/02/fuel-subsidies-completelyoverhauled.html [Accessed on 15 May 2015].

[30] Bloomberg. Malaysia Scraps Fuel Subsidies as Najib Ends Decades-Old Policy. http://www.bloomberg.com/news/articles/2014-11-21/malaysia-scraps-fuel- 
subsidies-as-najib-ends-decades-old-policy [Accessed on 15 May 2015].

[31] Shi X, Kimura F. The Status and Prospects of Energy Market Integration in East Asia. In: Wu Y, KIMURA F, SHI X, editors. Energy Market Integration in East Asia: Deepen Understanding and Move Forward. Oxon, New York: Rutledge; 2014. p. 9-24.

[32] Itoh S. A New Era of Coal: The "Black Diamond" Revisited. 2014 Pacifi Energy Forum Working Papers. Wasington D.C.: Nabtional Bureau of Asian Research; 2014.

[33] APEC. Peer Review on Energy Efficiency in Brunei Darussalam. Tokyo: APEC Energy Research Center; 2013.

[34] Shi X. Energy Efficiencies in ASEAN region. In: Yan J, editor. The Handbook for Clean Energy SystemsVolume 6 - Sustainability of Energy Systems: Wiley; 2015.

[35] Tiglao R. High electricity costs root of our backwardness. http://www.manilatimes.net/high-electricity-costs-root-of-our-backwardness/66574/ [Accessed on 21 Aug 2014].

[36] Pacudan R, Chantanakome W, Mirmira S, Browne S, Julaihi J. Workshop on Policies, Feed-in Tariff Frameworks and Best Practices for Grid Connected Solar PV Projects (Proceedings). Bandar Seri Begawan: Brunei National Energy Research Institute; 2013.

[37] Fox News. Russia, Ukraine Dispute Leaves European Nations Without Gas. Fox News2009.

[38] IEA. Energy Technology Perspetive 2012. Paris: International Energy Agency; 2012.

[39] IEA Clean Coal Centre. Climate implications of coal-to-gas substitution in power generation. London: IEA Clean Coal Centre; 2015.

[40] Kojima S, Bhattacharya A. Pricing Reform and Enhanced Investment in the Energy Sector: A Way Towards East Asian Economic Development In: Kimura F, Shi X, editors. Deepen Understanding and Move Forward: Energy Market Integration in East Asia. Jakarta: Indonesia; 2011.

[41] Chang Y, Li Y. Power Generation and Cross-boarder Grid Planning for the Integrated ASEAN Electricity Market: A Dynamic Linear Programming Model. In: Wu Y, SHI X, Kimura F, editors. Energy Market Integration in East Asia: Theories, Electricity Sector and Subsidies. Jakarta: Economic Research Institute for ASEAN and East Asia; 2012. 